\title{
Contribuições dos estudos de implementação para a análise de políticas educacionais: uma breve discussão do contexto de implementação da BNCC ${ }^{1}$
}

\section{Implementation study contributions to education policy analysis: a brief discussion of the context of BNCC implementation}

\author{
Marina Meira* \\ Alicia Bonamino*
}

\begin{abstract}
RESUMO
Recorrendo a contribuições de autores do campo da ciência política e da administração pública, o presente texto traça um breve histórico dos estudos de implementação de políticas, originalmente divididos em duas abordagens consideradas antagônicas. Em seguida, explora um dos modelos de síntese desenvolvidos a partir dos anos 1990 para superar tal dicotomia (MATLAND, 1995), a fim de produzir uma análise inicial sobre a forma como as variáveis ambiguidade e conflito vêm sendo articuladas em políticas educacionais curriculares recentes, como os Parâmetros Curriculares Nacionais (PCNs) e a Base Nacional Comum Curricular (BNCC).
\end{abstract}

Palavras-chave: Implementação de políticas. BNCC. PCNs. Currículo.

\section{ABSTRACT}

By turning to contributions from the fields of Political Science and Public Administration, the present article aims to conduct a brief review on

$1 \mathrm{O}$ presente trabalho foi realizado com apoio da Coordenação de Aperfeiçoamento de Pessoal de Nível Superior (CAPES) - Código de Financiamento 001.

* Pontifícia Universidade Católica do Rio de Janeiro. Programa de Pós-Graduação em Educação. Rio de Janeiro, Rio de Janeiro, Brasil. E-mail: marina.meiraoliveira@gmail.com https://orcid.org/0000-0002-5713-2384 E-mail: aliciamcbonamino@gmail.com - https://orcid. org/0000-0001-8778-5362 
implementation studies, originally divided into two contrasting schools. It also discusses Matland's (1995) synthesizing model developed in the 1990s to reconcile such approaches, by articulating two important attributes by which policies are differentiated. Finally, it investigates how levels of conflict/ambiguity have varied in recent education policies, especially those focused on curriculum standards, such as the Parâmetros Curriculares Nacionais - PCNs [National Curricular Parameters] and Base Nacional Comum Curricular - BNCC [Common National Curricular Base].

Keywords: Policy implementation. BNCC. PCNs. Curriculum.

\section{Introdução}

Ao longo das últimas décadas, pudemos notar um interesse crescente pelas políticas públicas e seus efeitos nas vidas dos cidadãos. Esse interesse pode ser observado na proliferação de estudos sobre implementação, muito embora ainda sejam verificadas lacunas no tratamento do tema. Como pontua Lotta (2019), muitas vezes o termo "implementação" é empregado de forma metafórica, denotando apenas um momento de uma política, ou em substituição à ideia de execução, sem configurar um objeto de análise em si. Desse modo, concordamos com a autora no sentido de que a incorporação de modelos analíticos de implementação de políticas públicas poderia contribuir, em grande medida, para o aprimoramento desses estudos e o aumento de sua contribuição para o campo, a partir da ampliação de seu potencial de análise.

No caso específico das políticas educacionais brasileiras, os estudos de implementação realizados a partir de modelos analíticos que dialoguem, por exemplo, com referenciais da ciência política e da administração são ainda bastante incipientes. E isto contrasta, inclusive, com o maior desenvolvimento dos estudos de implementação de políticas nas áreas da saúde e da assistência social. Acreditando que esse diálogo pode ser profícuo, buscamos traçar um breve percurso dos estudos de implementação, explorando seu potencial de análise para estudos sobre políticas educacionais, e uma proposta de operacionalização para a análise do contexto de implementação de políticas curriculares recentes.

Reconhecemos, de início, que abundam revisões de literatura sobre implementação tanto no debate internacional (HILL; HUPE, 2014; HOWLLET; RAMESH; PEARL, 2013) quanto nacional (FARIA, 2012; LOTTA, 2019; BICHIR, 2020), com robustez significativamente maior do que a breve exploração conceitual e bibliográfica a que este artigo se propõe. No entanto, nosso objetivo consiste em dialogar mais especificamente com o campo educacional, no qual 
tais estudos têm sido escassos também por conta de uma disputa conceitual envolvendo a temática, que muitas vezes desconhece a origem e trajetória dos estudos de implementação. Muitas vezes percebida como uma etapa sequencial e executiva de diretrizes formuladas em escalões superiores, que elimina a ação crítica e criativa dos atores no campo das práticas, compreende-se a resistência por vezes observada à ideia de "implementação". Afinal, tal definição - que remonta a uma primeira geração de estudos na área, retomada neste artigo não faz jus à transformação pela qual passa uma política educacional, que é (re)interpretada, (re)articulada e ressignificada em diferentes contextos, para além daquele original de sua produção (MAINARDES; STREMEL, 2010).

Dessa forma, embora nosso principal foco de interesse seja a implementação de políticas, temos como propósito discutir de que modo esse processo há muito não configura uma mera etapa técnica e sequencial à formulação, cuja análise poderia ser feita de forma isolada do contínuo processo decisório que caracteriza a produção de políticas públicas. Pelo contrário, implementação é aqui compreendida como "interação entre atores no interior dos ambientes institucionais e relacionais presentes nas comunidades políticas" (LOTTA, 2014, p. 193), em que sentidos são negociados continuamente, desde os altos escalões até o nível da rua. A partir dessa proposta inicial de diálogo com o campo educacional, que torna pertinente este novo esforço de retomada e síntese, buscamos principalmente instrumentalizar essa discussão como uma possível lente de análise para iluminar aspectos da implementação de uma nova política educacional (a Base Nacional Comum Curricular - BNCC), em diálogo com processos análogos identificados anteriormente nos Parâmetros Curriculares Nacionais (PCNs).

Para tanto, além da introdução, o texto está organizado em quatro seções. $\mathrm{Na}$ primeira seção, abordamos duas perspectivas de análise desenvolvidas inicialmente no âmbito dos estudos organizacionais que tradicionalmente se apresentaram enquanto antagônicas. A segunda seção explora um dos modelos de síntese mais consolidados na literatura, desenvolvido na tentativa de superação dessa dicotomia. A terceira seção apresenta um esforço de transposição dos princípios analíticos desse modelo de síntese para a investigação dos diferentes contextos que têm caracterizado a implementação de duas políticas educacionais relevantes na esfera curricular: os PCNs e a recente BNCC. O texto se encerra com as considerações finais, retomando a trajetória dos estudos em implementação, que avançaram para além da dicotomia top-down (de cima para baixo) e bottom-up (de cima para baixo) e, até mesmo, dos modelos de síntese entre as duas abordagens, e passaram a incorporar o debate sobre governança multinível. Esta, por sua vez, apresenta um importante potencial de análise para estudos futuros que contemplem a implementação propriamente dita da BNCC. 


\section{A análise de políticas públicas e sua implementação: origens e trajetórias iniciais}

Em um estudo de revisão do cenário internacional que contemplou os trinta anos anteriores à sua publicação, Barret (2004) indica a prevalência, até a década de 1970, de análises centradas no processo de decisão e elaboração de políticas públicas. A preferência por tal recorte estaria ancorada em uma lógica weberiana de funcionamento do Estado, que prevê uma separação clara entre a esfera política (da decisão) e administrativa (da execução). Dentro dessa perspectiva, a fase da implementação dificilmente despertaria curiosidade investigativa, uma vez que seria concebida enquanto atividade meramente operacional, de execução de diretrizes.

A partir do final dos anos 1960, no entanto, no contexto de Guerra Fria e de disputas por modelos de Estado, passa-se a observar uma preocupação crescente com a efetividade das políticas e seus resultados. Ao analisar o desenvolvimento dos estudos de políticas públicas nos Estados Unidos, Sabatier (1993) identificou uma geração pioneira nos estudos de implementação surgida nos anos 1970, no contexto de consolidação dos programas de combate à pobreza, tendo como referência o estudo de caso de Pressman e Wildavsky (1973) sobre a implementação de um programa na cidade de Oakland (Califórnia). Se, inicialmente, a ideia de implementação pressupunha que a decisão de uma autoridade seria automaticamente cumprida, o mérito do estudo de Pressman e Wildavsky foi demonstrar o quanto, apesar da decisão do nível central, a operacionalização do programa apresentava inúmeros percalços no nível local. Essa primeira geração dos estudos de implementação nos anos de 1970 foi chamada de top-down e enfocou detalhadamente os acontecimentos empreendidos por uma única instância de autoridade decisória, caracterizandose pelos estudos de caso centrados, especialmente, na identificação dos obstáculos à implementação.

Uma de suas principais preocupações era, portanto, entender por que as políticas "falham" - partindo do pressuposto de que o sucesso de uma política seria medido em relação ao grau de alcance de seus objetivos pré-estabelecidos. Nesse sentido, a tomada de decisão por parte de um agente não considerado legítimo para tanto (burocrata) poderia ser vista como um desses fatores explicativos, além de ser considerada uma distorção da autoridade hierárquica.

Autores como Sabatier e Mazmanian (1979) também buscaram identificar elementos-chave na formulação das políticas que estariam contribuindo para que fosse aberto esse espaço de agência no curso da implementação. Dentre eles, estavam a falta de clareza de seus objetivos, que permitia diferentes 
interpretações e ações discricionárias; uma multiplicidade de atores envolvidos na implementação, potencialmente gerando problemas de comunicação e coordenação; diferenças entre os valores e interesses organizacionais, que dificultavam o estabelecimento de prioridades; e a relativa autonomia e discricionariedade das agências implementadoras, que impunham limites ao controle administrativo. Tendo como base uma premissa normativa/prescritiva, à identificação desses elementos seguia-se uma série de recomendações para garantir o alcance dos objetivos pré-definidos, a exemplo da minimização do número de atores, a regulação da discricionariedade dos agentes implementadores, e a tentativa de atribuir a implementação da política a agências alinhadas com seus objetivos.

Na sequência, novos estudos que compartilhavam a perspectiva topdown buscaram explicar as diferenças nas implementações de programas governamentais, privilegiando processos decisórios de alto nível, leis e arranjos formais do delineamento da política, tidos como a principal referência para acompanhar a implementação bottom-up. A finalidade dos estudos continuava sendo, portanto, entender como os objetivos formulados poderiam ser alcançados, sendo a implementação analisada como barreira explicativa (BICHIR, 2020).

Como apontado por Matland (1995), os pesquisadores que adotam essa linha costumam ser alvo de três tipos principais de críticas: 1) o modelo despreza a relevância das ações e dinâmicas prévias à implementação; 2) o olhar sobre a implementação enquanto um processo meramente administrativo ignora (ou busca eliminar) aspectos políticos; e 3) os formuladores da política ganham destaque enquanto os atores principais e com maior legitimidade no processo de análise, ao passo que os agentes implementadores são comumente tratados como um obstáculo ao sucesso da implementação.

Como pontua Bichir (2020), as principais críticas à abordagem topdown se referem a um excessivo racionalismo e simplismo do modelo, que se apresenta demasiadamente otimista quanto à capacidade dos formuladores de estruturar a implementação, sem considerar os pontos de resistência e conflito e o elemento político implicado tanto na formulação, quanto na implementação (WINTER, 2006).

Com base nessas críticas, desenvolveu-se, no início da década de 1980, a perspectiva bottom-up (de baixo para cima), que demarca a segunda geração dos estudos de implementação. Essa perspectiva se destaca por deslocar seu foco do "topo" para a "base" da hierarquia político-administrativa, ou seja, para as interações cotidianas em que as políticas e os serviços são entregues para os usuários, com ênfase na burocracia de linha de frente (street-level bureaucracy) (SABATIER, 1993; WINTER, 2006 apud BICHIR, 2020). 
Compreendendo a criação de políticas como um "processo iterativo de formulação, implementação e reformulação" (MAZMANIAN; SABATIER, 1983, p. 9, tradução nossa), a implementação não mais é concebida como uma etapa adicional e sequencial ao longo da evolução da política, mas como um processo criativo em que as organizações locais reagem aos planos desenhados em nível macro e, a partir de então, desenvolvem seus próprios programas e os implementam (MATLAND, 1995, p. 148). O parâmetro para avaliar o sucesso de uma política torna-se, assim, menos dependente dos objetivos iniciais, cuja relevância é secundarizada diante dos processos empreendidos nos contextos em que a mesma é implementada, dos quais dependem os resultados.

A discricionariedade exercida pelos agentes implementadores também é ressignificada enquanto um mecanismo adaptativo inevitável e até mesmo desejável, justamente por possibilitar que determinadas normativas - muitas vezes "irrealistas" e pouco exequíveis (MAYNARD-MOODY; MUSHENO, 2003, p. 24) - possam ser adaptadas às circunstâncias da implementação, produzindo efeitos positivos. Tendo sido considerada na abordagem top-down como um dos principais fatores que levam a falhas e ao fracasso de uma política, a margem de liberdade concedida aos burocratas da ponta passa a ser compreendida como um fator necessário ao sucesso dos programas, que dependeriam em grande parte da capacidade adaptativa desses indivíduos. Os formuladores no nível central, portanto, influenciariam apenas parcial e indiretamente os processos conduzidos no nível local, o que poderia explicar por que uma mesma política nacional apresenta variações a depender dos contextos de implementação.

O destaque no modelo bottom-up recai sobre os agentes locais, que passam a constituir "variável explicativa" do processo de implementação. Um dos trabalhos seminais nessa área é a obra de Michael Lipsky (1980), que define como "burocratas de nível de rua" os agentes da linha de frente do serviço público que interagem diretamente com os cidadãos-usuários ao longo de seu trabalho (policiais, professores, assistentes sociais etc.). A relativa liberdade que esses agentes teriam para determinar a natureza, quantidade e qualidade dos benefícios e sanções distribuídas aos diferentes cidadãos - denominada discricionariedade (LIPSKY, 1980, p. 13) - contribuiria para que eles fossem considerados não apenas executores, mas "fazedores de política". Ao passo que Lipsky (1980) ressaltava a relevância da discricionariedade enquanto um mecanismo adaptativo e de autopreservação em meio a um contexto de sobrecarga de trabalho e escassez de recursos, autores como Maynard-Moody e Musheno (2003) enfatizam outras racionalidades que podem orientar a ação discricionária dos implementadores, destacando a influência de valores morais na construção de percepções sobre os diferentes usuários, e na tomada de decisões alocativas sobre aquilo de que necessitam ou que "merecem" acessar. 
A abordagem bottom-up também recebe críticas, dentre as quais duas se destacam (MATLAND,1995). A primeira enfatiza que, em uma democracia, o controle sobre a política deve ser exercido pelos agentes que têm legitimidade para tanto, ao terem sido eleitos (ou escolhidos como representantes desses eleitos) para tomar decisões e formular planos de ação, sendo assim responsabilizados pelos seus resultados. Algum nível de flexibilidade e autonomia poderia ser apropriado quando houvesse um alinhamento entre os objetivos dos formuladores e implementadores. No entanto, se o que prevalecem são as divergências entre esses agentes, a liberdade de ação na ponta poderia resultar em baixa performance de implementação. A segunda crítica sugere que os estudos bottom-up atribuem uma ênfase exacerbada à autonomia no nível local, ao passo que, na realidade, uma parte significativa dessa margem de ação pode ser prevista (e manipulada) por atores mais centrais que têm a capacidade de estruturar os contextos de implementação de tal forma, que os objetivos e as estratégias adotadas pelos agentes na ponta também sejam afetados. Portanto, a estrutura institucional em que os burocratas implementadores atuam e os recursos disponibilizados para tanto seriam elementos-chave a condicionar suas decisões e ações, consequentemente influenciando os resultados da política.

Especialmente a partir dos anos 1990, no contexto da chamada terceira geração dos estudos de implementação, desenvolveram-se esforços de síntese das duas abordagens. Tais tentativas buscaram combinar a análise de estruturas de implementação e de incentivo com o olhar para os atores locais, seus objetivos, valores e dinâmicas relacionais. Em que pese o reconhecimento pela literatura da importância do contexto para explicar os processos de implementação, poucos autores efetivamente avançaram na compreensão das variáveis contextuais que influenciam de forma significativa a execução das políticas. Na seção a seguir, destacamos as contribuições de Matland (1995), um dos autores que mais se dedicaram à compreensão dos efeitos do contexto sobre a implementação (LOTTA et al., 2021).

\section{Contextos propícios para a operacionalização das diferentes abordagens: articulando ambiguidade e conflito na implementação de políticas públicas}

A partir de uma análise robusta da literatura sobre as abordagens top-down e bottom-up, Matland (1995) propõe-se a um esforço de síntese que busca a criação de um novo modelo explicativo dos contextos de implementação em 
que uma ou outra forma de análise se mostra mais apropriada. O autor parte do princípio de que pesquisadores filiados às duas linhas tradicionais tendem a estudar políticas de diferentes tipos: os top-downers, políticas relativamente mais claras; os bottom-upers, políticas com maior grau de incertezas. No entanto, se a implementação é compreendida como um contínuo processo decisório, faz-se necessário olhar para duas variáveis chave que afetam a tomada de decisão dos atores: conflito e ambiguidade.

Para Matland (1995), os top-downers percebem o conflito como uma variável endógena à política pública, que pode ser influenciada e minimizada pelos formuladores, ao passo que os bottom-upers o percebem como algo dado e não manipulável. Segundo o autor, alguns tipos de conflito - sejam eles referentes à finalidade de uma política e/ou aos meios planejados para atingi-la - poderiam ser, de fato, contornáveis, por meio da oferta de incentivos financeiros que levassem os atores-chave a aderirem à proposta. Outros conflitos, no entanto, não seriam ajustáveis mediante injeção de recursos, porque estariam baseados em uma incompatibilidade significativa de valores. Nesses casos, mecanismos de barganha e coerção seriam mais comumente usados para garantir conformidade.

A ambiguidade, enquanto grau de incerteza da política, também pode estar relacionada a meios e fins, e apresentar relação estreita com a dimensão do conflito. Nesse caso, Matland (1995) chama atenção para os efeitos conflituosos que podem ser gerados pela recomendação típica dos modelos top-down de que os objetivos e procedimentos de uma política devem ser claros, deixando pouca margem para dúvida, de modo a influenciar positivamente seu sucesso. A realidade do contexto de implementação pode, na verdade, apresentar uma dinâmica oposta, em que conflito e ambiguidade são inversamente proporcionais. Quanto mais claros e bem definidos os objetivos de uma política para gerar mudanças em um dado contexto, maior seria a chance de que levassem a conflitos, no sentido de que os atores poderiam se sentir ameaçados em relação à margem de ação de que dispõem em seu "território" e à capacidade de manter determinados padrões de poder no nível local. Nesse caso, a elevação da ambiguidade poderia ser um mecanismo de redução de conflito, e o modo de garantir a implementação de uma política. Uma dinâmica parecida também poderia ocorrer na esfera da formulação, considerando a necessidade de aprovação da política por diferentes atores do legislativo.

No que diz respeito aos meios, a ambiguidade pode tornar-se mais evidente quando a tecnologia necessária para atingir os objetivos é inexistente, ou quando há pouca certeza sobre os papéis que cada organização deve desempenhar no processo de implementação. É possível, ainda, que o contexto seja muito complexo, a ponto de dificultar o reconhecimento dos instrumentos, do seu uso e dos seus efeitos. 
De acordo com Matland (1995, p. 159), a implementação de políticas ambíguas é um fato, tanto no que diz respeito a seus objetivos quanto aos meios para alcançá-los. O nível em que essa variável se faz presente impacta direta e significativamente o processo de implementação de diferentes formas, afetando a capacidade de monitoramento das atividades e a probabilidade de que a política seja compreendida da mesma forma nos diferentes locais em que é implementada.

Matland (1995) observa o contexto de política pública como estando marcado por graus diferentes de conflito e ambiguidade, e considera que a interdependência entre esses elementos gera contextos mais ou menos favoráveis a implementações efetivas. Mais especificamente, o autor propõe uma matriz em que cada quadrante representa um "tipo ideal" de contexto de implementação, acompanhado do princípio central que determinaria os resultados em cada caso.

FIGURA 1 - CONTEXTOS DE IMPLEMENTAÇÃO SEGUNDO O GRAU DE AMBIGUIDADE-CONFLITO

\begin{tabular}{|c|c|c|c|}
\hline & \multicolumn{2}{|c|}{ Conflito } \\
\hline & & Baixo & Alto \\
\hline \multirow{2}{*}{ Ambiguidade } & Baixa & $\begin{array}{c}\text { Implementação Administrativa } \\
\text { Recursos }\end{array}$ & $\begin{array}{c}\text { Implementação Política } \\
\text { Poder }\end{array}$ \\
\hline & Alta & $\begin{array}{l}\text { Implementação Experimental } \\
\text { Condições contextuais }\end{array}$ & $\begin{array}{l}\text { Implementação Simbólica } \\
\text { Força de Coalizões }\end{array}$ \\
\hline
\end{tabular}

FONTE: Matland (1995, p. 160, tradução nossa).

O contexto de implementação administrativa é característico de políticas que apresentam baixo grau de conflito e de ambiguidade. Uma vez que há consenso sobre os objetivos e os meios de alcançá-los, e que esses meios são existentes e conhecidos, o principal fator a determinar os resultados são os recursos disponíveis. Há uma autoridade que dispõe de recursos, informações e capacidade de estabelecer sanções de modo a fazer a política operar. O fluxo de informação parte de cima para baixo, atingindo atores que têm uma ideia clara de quais são seus papéis, sem apresentar grandes resistências à ação. Nesse sentido, as abordagens top-down tradicionais se apresentam como boas chaves de análise para explicar o processo de implementação, que segue uma lógica weberiana.

No contexto de implementação política, o nível de ambiguidade permanece baixo, mas há um conflito elevado a respeito dos objetivos e/ ou instrumentos. Tal conflito normalmente remonta a estágios anteriores, e o principal elemento a determinar "quem vence" a disputa é o poder dos atores, seja para impor sua vontade nos diferentes níveis hierárquicos ou para negociar com atores de diferentes camadas decisórias (HILL; HUPE, 2003). 
O processo de implementação consiste, em última instância, em garantir a obediência/conformidade dos atores de cujos recursos o sucesso da política depende, tornando os mecanismos coercitivos ou remunerativos, portanto, predominantes. Matland (1995) considera que os novos modelos top-down podem contribuir de maneira significativa para a compreensão do que ocorre nesses contextos, uma vez que, diferente de abordagens mais tradicionais, fatores políticos são enfatizados.

No contexto de implementação experimental, o grau de conflito é baixo porque há um consenso geral sobre a necessidade da política, mas o grau de ambiguidade é alto em razão das incertezas dos atores em relação a seus objetivos específicos e/ou aos melhores instrumentos a serem adotados. Nesse cenário, os resultados dependem principalmente de quais atores estão mais envolvidos e ativos em cada contexto local. Como as condições contextuais são o principal fator a influenciar a implementação, podem verificar-se processos e resultados bastante diversos, uma vez que o conjunto de atores envolvidos e as pressões que recaem sobre eles são diferentes. Em contextos experimentais, há uma margem considerável para a inovação e para o desenvolvimento de novas capacidades, de forma que, na perspectiva de Matland (1995), as abordagens bottom-up são melhores do que as top-down para sua análise, uma vez que as últimas apresentam pouca tolerância à ambiguidade, e enfatizam elementos como controle, comando e uniformização - que não cabem em contextos de implementação experimental.

Por fim, ainda que pareça pouco provável que uma política apresente um alto nível de ambiguidade e conflito - uma vez que um aumento na ambiguidade pode contribuir para a redução de conflito - contextos de implementação simbólica também podem ocorrer. Trata-se de políticas cujos símbolos (os temas/assuntos a que se referem) costumam produzir muitos dissensos, mesmo quando a política em si é bastante aberta ou vaga. Nestes contextos em que a dimensão do conflito se torna importante ao estruturar a forma como as resoluções serão desenvolvidas, o principal elemento a determinar os resultados é a força das coalizões formadas por atores locais que controlam os discursos disponíveis. Em meio a objetivos vagos e abstratos, observam-se diferentes interpretações em disputa sobre a forma "correta" de traduzi-los em ações, dando origem à competição entre coalizões. Por ser eminentemente conflituosa, a implementação simbólica se assemelha, em certa medida, à implementação política, principalmente no que diz respeito ao emprego de mecanismos de coerção e barganha para resolver dissensos. O principal diferencial desse contexto é o fato de que são as coalizões no nível micro (local) e não macro (central) que têm maior influência sobre os resultados. Nesses casos, identificar os grupos em competição no nível local, bem como os fatores contextuais que 
afetam as forças desses grupos, é algo central para a melhor compreensão de seus resultados. Nem modelos top-down, nem modelos bottom-up são totalmente apropriados para a descrição desse tipo de cenário.

Em suma, o modelo proposto por Matland (1995) parte do princípio de que tanto abordagens top-down quanto bottom-up trazem contribuições importantes para a compreensão das diferentes situações de implementação, sendo que, em determinados contextos, uma ou outra pode ser mais apropriada. Para o autor, é a análise dos níveis de conflito e ambiguidade de uma política que pode possibilitar previsões sobre a forma como a implementação se desenvolverá.

Na seção a seguir, buscamos realizar uma apropriação inicial desse modelo na compreensão do contexto de implementação de uma política educacional recente, que tem como um de seus traços distintivos o elevado nível de conflito que a envolve desde a formulação.

\section{Base Nacional Comum Curricular e seu contexto de implementação: possibilidades de operacionalização de conceitos}

A Base Nacional Comum Curricular, homologada em 20 de dezembro de $2017^{2}$, previa um período de estruturação entre 2018 e 2019 , com vistas a ser implementada nas escolas de todo o país a partir de $2020^{3}$. O caráter recéminiciado de sua implementação não permite análises robustas dos processos empreendidos e dos resultados que vêm sendo alcançados. No entanto, é possível lançar um olhar inicial sobre seu contexto de implementação, ou seja, sobre as condições que se apresentam para esse processo e sobre os fatores que têm maior potencial de influenciar a atuação no nível local.

Para tanto, em linha com Matland (1995), acreditamos que a análise sobre a implementação da BNCC deve levar em conta os antecedentes da política, que podem remeter a disputas travadas em momentos anteriores de sua produção (WINTER, 1985). Dessa forma, buscamos realizar uma breve retrospectiva dos

2 À exceção da parte do documento referente ao Ensino Médio, que foi profundamente alterada a partir da chamada "Reforma do Ensino Médio", tendo sido homologada aproximadamente um ano depois.

3 Diante dos desafios trazidos pela grave pandemia do novo coronavírus no ano de 2020, que incluíram o fechamento de milhares de escolas no país, presume-se que a implantação efetiva passe a ocorrer de forma mais significativa a partir do ano 2021. A análise desse processo, no entanto, ultrapassa o escopo do presente trabalho. 
marcos legais que lhe serviram de fundamentação, e que deram origem a políticas curriculares anteriores, cujos contextos de implementação foram diversos diante de níveis diferenciados de conflito e ambiguidade.

Promulgada após um longo período de ditadura militar, a Constituição Federal de 1988 estabelece a educação enquanto um direito fundamental do cidadão e um dever a ser compartilhado entre Estado, família e sociedade. No Artigo 210, o documento prevê a fixação de "conteúdos mínimos para o ensino fundamental, de maneira a assegurar formação básica comum e respeito aos valores culturais e artísticos, nacionais e regionais" (BRASIL, 1988). Tal artigo servirá como um dos pontos de partida para a elaboração da Lei de Diretrizes e Bases da Educação (LDB) de 1996, que, no Artigo 9 (Inciso IV), incumbe a União de

estabelecer, em colaboração com os Estados, o Distrito Federal e os Municípios, competências e diretrizes para a educação infantil, o ensino fundamental e o ensino médio, que nortearão os currículos e seus conteúdos mínimos, de modo a assegurar formação básica comum (BRASIL, 1996).

É importante observar, desde esse primeiro momento, a dimensão de múltiplas camadas (HILL; HUPE, 2003) que assume uma política educacional responsável por prever uma base comum de competências e conteúdos em nível nacional. Ao reconhecer a necessidade de articulação com outras esferas de decisão subnacionais, pode-se inferir a legitimidade de estados e municípios no processo de elaboração dessas diretrizes gerais, bem como na definição de seus currículos específicos, sem contar o papel que viriam a assumir em sua implementação.

Ainda no final dos anos 1990, no contexto da nova LDB, foi desenvolvido, pela primeira vez em nível nacional, um conjunto de documentos referenciais da educação básica: os Parâmetros Curriculares Nacionais. Uma primeira diferença importante que pode ser observada entre os PCNs (1997) e a BNCC é que os primeiros se constituíram em referenciais abertos e não obrigatórios, tendo apenas um caráter indutor da renovação das propostas curriculares das redes de ensino, das escolas e da formação docente. Como apontado pelo ministro da Educação e Desporto à época - Paulo Renato Souza - na mensagem ao professor que inaugura a introdução aos PCNs, os referenciais "são abertos e flexíveis, podendo ser adaptados à realidade de cada região" (BRASIL, 1997). 
Quando localizamos historicamente a época de elaboração dos PCNs, o pós-ditadura, notamos um esforço para evitar que a política fosse percebida enquanto uma medida top-down que configurasse um "modelo curricular homogêneo e impositivo", visto que:

$\mathrm{Na}$ sociedade democrática, ao contrário do que ocorre nos regimes autoritários, o processo educacional não pode ser instrumento para a imposição, por parte do governo, de um projeto de sociedade e de nação. Tal projeto deve resultar do próprio processo democrático, nas suas dimensões mais amplas, envolvendo a contraposição de diferentes interesses e a negociação política necessária para encontrar soluções para os conflitos sociais (BRASIL, 1997, p. 27).

Tendo como referência o modelo de Matland (1995), é possível caracterizar os PCNs enquanto uma política que apresentava alto grau de ambiguidade (diante de seu caráter "aberto e flexível") e, por conta dessa mesma característica, um baixo grau de conflito.

No que diz respeito aos seus objetivos, a ambiguidade aparece já no texto introdutório, segundo o qual os objetivos gerais do Ensino Fundamental (assim como os de cada área para esse segmento) "são suficientemente amplos e abrangentes para que possam conter as especificidades locais" (BRASIL, 1997, p. 70). No que diz respeito aos meios, cabe ressaltar, por exemplo, a maior abertura oferecida pela proposta de organização do ensino em ciclos, a fim de evitar uma fragmentação excessiva e permitir um trabalho mais flexível.

No tocante à dimensão do conflito, que tenderia a diminuir em razão da alta ambiguidade da política, cumpre destacar que o período de redemocratização em que os PCNs foram formulados estimulou o compartilhamento de expectativas e certo nível de concordância em torno da necessidade de participação democrática em diferentes instâncias, e da promoção de modificações no sistema educacional, a fim de ampliar e melhorar o atendimento da escola pública. Outro fator que possivelmente contribuiu para o baixo nível de conflito em torno dos PCNs foi a declaração de seu caráter não obrigatório por parte do Conselho Nacional de Educação, quando da elaboração das Diretrizes Curriculares Nacionais (BONAMINO; MARTÍNEZ, 2002).

Muito embora fuja ao escopo deste trabalho, é importante destacar que não se trata de afirmar a ausência de conflitos durante a formulação dos PCNs, sobretudo quando levamos em conta as tensões que se estabeleceram entre MEC e CNE ao longo desse processo, exploradas em detalhes por 
Bonamino e Martínez (2002). Tais tensões acabaram por culminar justamente na declaração que afirmava o caráter apenas facultativo desses parâmetros. No entanto, naquele contexto, diferentemente do contexto da BNCC, pode-se dizer que houve um nível considerável de consenso em relação à necessidade de referenciais para a educação brasileira, e à forma aberta, flexível e "ambígua" que os parâmetros adotaram.

Nesse sentido, a política curricular e seus estágios iniciais de produção abriram caminho para um contexto experimental de implementação, que resultou na diversidade de programas (currículos) e práticas realizadas por diferentes atores em camadas ou níveis locais (estados, municípios e escolas). No geral, pode-se dizer que os PCNs tiveram "grande aceitação, sobretudo no que dizia respeito ao Ensino Fundamental” (TILIO, 2019, p. 7).

Já a atual BNCC resulta de processos razoavelmente distintos. Seguindo a linha cronológica iniciada nesta seção com a referência à Constituição de 1988, à LDB de 1996, e aos PCNs de 1997-1998, cabe mencionar a sanção da Lei 13.005, em 25 de junho de 2014 (BRASIL, 2014), que regulamenta o Plano Nacional de Educação (PNE). O Plano tem vigência até 2024 e apresenta 20 metas e um conjunto de estratégias para a melhoria da qualidade da Educação Básica, dentre as quais quatro se referem à construção de uma base nacional curricular comum. Em meio a esse novo cenário de discussões sobre a definição de conteúdos mínimos a serem acessados por todos os alunos no território nacional, aos quais seriam acrescentadas as especificidades de cada região, já é possível observar dissensos consideravelmente maiores do que os observados no período de redemocratização do país.

Desde o início, observa-se um nível significativo de conflito em relação à possibilidade/pertinência de alguma política de padronização curricular em meio a um cenário de grande diversidade sociocultural, como o Brasil. Em estudo publicado pelo Centro de Estudos e Pesquisas em Educação, Cultura e Ação Comunitária (CENPEC) em 2015, ano em que estava em andamento a formulação da primeira versão da BNCC, foi possível verificar a ausência de um consenso entre atores ligados ao campo educacional (gestores e professores da educação básica e superior, sindicalistas e setores da sociedade civil, por exemplo) em relação ao que se entendia por currículo e por base curricular, além de um contínuo entre opiniões absolutamente favoráveis ou contrárias a certa padronização de conteúdos no país. Posicionamentos mais próximos ao polo favorável eram encontrados principalmente entre os agentes ligados a organizações da sociedade civil, gestores educacionais, e alguns professores da educação básica. Os posicionamentos majoritariamente contrários, por sua vez, estavam mais presentes no campo acadêmico (professores e pesquisadores do Ensino Superior, membros de comissões avaliadoras de cursos, etc.) e 
entidades científicas e sindicais, a exemplo da Confederação Nacional dos Trabalhadores em Educação.

Como aponta Cossentin (2017), por um lado, a proposta tende a ser vista de forma positiva por aqueles que enfatizam a universalidade da educação e do direito a ela enquanto garantia de acesso à igualdade e inclusão social. Nesse sentido, atribui-se à escola um importante papel na diminuição das desigualdades sociais enquanto instituição republicana e democrática. Por outro lado, a proposta tende a ser considerada prejudicial à garantia do direito à diferença e pouco condizente com a realidade educacional do país, marcada por contingências locais e ampla diversidade cultural. Um dos principais argumentos que embasam os posicionamentos contrários à proposta - marcadamente mais expressivos, conforme aponta a autora - é o risco de que essa diversidade seja sacrificada em prol de uma uniformização incoerente com a realidade dos diferentes contextos de implementação, contribuindo para reforçar desigualdades já existentes. Para Süssekind (2014), por exemplo, a padronização nacional de conteúdos gera uma "linha abissal" em relação aos currículos pensados e praticados nas escolas, que são colocados em posição de invisibilidade, além de promover um controle estatal prejudicial à garantia da autonomia docente, um ponto também levantado por outros atores contrários à política, a exemplo dos sindicatos de profissionais da educação.

Os conflitos que envolvem as discussões sobre a BNCC desde sua elaboração foram também ampliados por dois fatores. Um deles foi a alta normatividade (ou baixa ambiguidade) estabelecida pela política - sobretudo no segmento do Ensino Fundamental - que, diferentemente do que ocorria com os PCNs ou com as Diretrizes anteriores, estabelece expectativas de aprendizagem, competências e habilidades específicas para cada disciplina e área do conhecimento, acompanhadas de uma seleção de conteúdos que devem ser ensinados em cada série escolar. Além disso, e talvez o mais importante, o conflito em torno da proposta vem sendo agravado pelo questionamento da legitimidade de seus formuladores e pelo modo impositivo ("de cima para baixo") com que a reforma curricular estaria sendo conduzida.

Ao passo que a redação das duas versões preliminares da BNCC contou com um pouco mais de participação popular, por meio de contribuições reunidas em uma plataforma online, a elaboração da terceira (e última) versão sofreu alterações relevantes, como a própria introdução dos termos competências e habilidades em substituição aos termos objetivos e direitos de aprendizagem presentes na primeira e segunda versão da BNCC. Além disso, essas alterações ocorreram após um processo extremamente conturbado de destituição de uma presidente eleita e sua substituição por um vice-presidente com baixa legitimidade democrática. A partir de então, as coalizões de atores que ganharam 
destaque no processo de (re)elaboração do documento no âmbito do novo governo também têm sido alvo de críticas. Alguns desses atores fazem parte dos chamados "reformistas empresariais da educação" (FREITAS, 2014) e da "nova filantropia" ligada ao setor educacional (AVELAR; BALL, 2019) - empresas, fundações e institutos privados que muitas vezes percebem a Educação Básica como um mercado potencialmente lucrativo, e cujas articulações em prol da Base vêm sendo observadas desde o início dos debates sobre a política, tendo adquirido um protagonismo crescente em sua produção desde então (COSTA, 2018). Apesar das profundas controvérsias suscitadas, esses novos atores tiveram força suficiente para garantir a aprovação e a homologação da versão final do documento em dezembro de 2017.

A breve explicitação do percurso acima sugere que a implementação da BNCC possivelmente será caracterizada por um contexto político segundo o modelo de Matland (1995). Como discutido, o cenário que se apresenta é de uma política marcadamente conflituosa em relação a meios e fins, desde as etapas iniciais de sua produção, e pouco ambígua no seu formato final, o que contribui para o agravamento do conflito. $\mathrm{O}$ fator poder tende a ser, portanto, um elemento-chave na definição de "quem vence" as disputas acerca da proposta. Nesse cenário, como pontua o autor, o processo de implementação gira em torno dos esforços em garantir a conformidade daqueles que dispõem de recursos para a concretização da política, uma vez que, diante de visões e valores opostos, essa anuência não pode ser dada como certa.

A partir de uma análise com base em novos modelos top-down, uma possibilidade de estudo futuro seria, por exemplo, mapear quais são os mecanismos coercitivos e/ou remunerativos que o nível central vem promovendo na tentativa de garantir a reelaboração dos currículos estaduais, municipais, ou dos projetos político-pedagógicos das escolas com um alinhamento à política, e quais resultados são produzidos. Outro lócus possível de investigação são as estratégias em busca de apoio (popular e/ou de parceiros relevantes) que vêm sendo traçadas, bem como a seleção das agências simpatizantes com a proposta para participarem da coordenação da implementação da política. Nesse sentido, cabe um destaque para o papel assumido por editoras, institutos e fundações filantrópicas, por exemplo, na produção de material didático e de divulgação/ promoção da política, bem como nos alinhamentos conceituais e orientações metodológicas, e também na formação de professores.

Muito embora o contexto de implementação da BNCC esteja sendo "tipificado" como político no presente trabalho, nada impede que investigações empíricas elejam como foco de análise os chamados "burocratas do nível da rua” e suas formas de recepção e (re)ação diante da proposta. Aliás, é possível dizer que os próprios formuladores e agências interessadas na implementação da 
política têm ciência de que, embora haja objetivos e instrumentos explicitamente definidos, os recursos essenciais estão nas mãos dos atores de quem depende seu efetivo sucesso, e que podem se opor à proposta oficial. Os dois trechos abaixo - retirados do Guia de Implementação da BNCC e de um material de referência pedagógica para gestores e professores elaborado pela Editora Moderna - ilustram essa situação:

Informar todos os envolvidos, sobretudo professores, é fundamental para o sucesso da implementação. Essa estratégia confere legitimidade ao processo e ao resultado, evita resistências e apoia os professores das escolas públicas e privadas a colocar o novo documento curricular em prática na sala de aula (BRASIL, 2020, p. 18, grifos nossos).

Será necessário articular Estados e municípios, gestores públicos, diretores, especialistas, programas de formação, produzir materiais educativos, mas especialmente será necessário mobilizar o profissionalchave da Educação: o professor. Se os educadores não comprarem o desafio, a BNCC corre o risco de ser ignorada, transformar-se em um roteiro empobrecido da educação e se afastar do seu objetivo central: promover oportunidades iguais, assegurando o direito à aprendizagem (EDITORA MODERNA, 2018, p. 18, grifos nossos).

Por fim, cumpre lembrar que há sempre a possibilidade de uma dada política ser "deslocada" de um quadrante para outro, com base no modelo de Matland (1995). No caso da BNCC, por exemplo, se houver um enfraquecimento na coligação de forças que busca garantir a implementação de suas (conflituosas) normativas e uma queda nos recursos disponíveis para tanto, é possível que se configure um contexto de implementação simbólica, gerando poucas mudanças nos níveis locais. Nesse sentido, é importante lembrar as considerações do próprio autor a esse respeito (MATLAND, 1995, p. 164-165): no âmbito legislativo da aprovação de uma política, uma coalizão comumente consiste em atores cujo apoio é transitório, baseado em troca de favores ou pressão política. No entanto, muitos deles têm pouco interesse efetivo em sua implementação, a qual pode acabar não acontecendo na prática. Ainda nessa linha de pensamento, desenha-se mais uma possibilidade de análise (dentre as muitas que existem) relacionada à forma como a transição de um governo para o outro vem impactando o apoio ao principal programa formulado para dar sustentação à implementação da Base Nacional Comum Curricular (o Programa de Apoio à Implementação da Base Nacional Comum Curricular - ProBNCC) a partir do repasse, ou não, de 
recursos. Uma situação de contingenciamento ${ }^{4}$ poderia, por exemplo, contribuir para o deslocamento de um contexto de implementação política para simbólica.

\section{Considerações finais}

O presente trabalho buscou, em primeiro lugar, retomar a origem dos estudos de implementação e traçar um breve percurso de sua trajetória inicial, buscando entender de que forma a implementação tornou-se uma preocupação central dos estudos em políticas públicas e deixou de ser compreendida como mera execução. Recorrendo a contribuições inicialmente concentradas nos campos da ciência política e dos estudos organizacionais - e que vêm, cada vez mais, adquirindo um caráter multi/interdisciplinar a partir da articulação de diferentes lentes teóricas - destacamos que as motivações iniciais para o estudo da implementação apresentavam um caráter normativo. Em outras palavras, buscava-se compreender que fatores levam a falhas nas políticas, de modo a eliminá-los e, assim, garantir o alcance dos objetivos estipulados.

Em seguida, exploramos duas das principais abordagens que marcaram o início dos estudos desenvolvidos para analisar esses processos: a top-down, com um enfoque claro no processo de formulação das políticas, e a bottom-up, que elege como principal foco os atores da ponta do serviço público, também conhecidos como "burocratas de nível de rua” (LIPSKY, 1980). Após um longo período de disputa entre as duas perspectivas analíticas, em que se enfatizaram tanto seus limites quanto suas potencialidades, modelos de síntese começam a surgir, numa tentativa de combinar elementos de ambas as abordagens ou de apresentar situações em que cada uma delas se tornaria mais apropriada. Dentre eles, destacamos o modelo de Matland (1995), que busca articular duas variáveis comumente presentes no processo de produção de políticas - ambiguidade e conflito - com vistas a identificar os diferentes contextos de implementação que são gerados a partir de sua articulação, em maior ou menor grau.

Por fim, buscamos realizar uma breve análise do contexto de implementação da Base Nacional Comum Curricular tomando como referência o modelo desenvolvido por Matland (1995). Nesse processo, procuramos traçar uma comparação do cenário que vem sendo desenhado desde os estágios iniciais

4 Um exemplo pode ser encontrado na matéria da Folha de São Paulo (SALDANHA, 2019), que trata do não repasse de recursos por parte do governo federal aos estados, para auxiliar no desenho de novos currículos e formação de professores. 
de produção da $\mathrm{BNCC}$ com processos análogos ocorridos com os PCNs, uma importante política curricular anterior, cujo contexto de implementação se mostrou diferente do atual.

Embora uma sistematização minuciosa da trajetória dos estudos em implementação ultrapasse o escopo deste trabalho, é fundamental pontuar que os estudos desenvolvidos nas últimas duas décadas transcendem a dicotomia topdown e bottom-up, superando, até mesmo, esforços de síntese que permaneçam atados a essa divisão binária. No que se costuma chamar de "quarta geração de estudos" (LOTTA, 2019), os debates principais sobre implementação exploram elementos como a governança multinível - os fluxos verticais e horizontais de interação entre atores estatais e não estatais (HILL; HUPE, 2003) - característica de um contexto de reformas e redefinição do papel do Estado, em que atores do setor privado ou do terceiro setor se fazem cada vez mais presente nas arenas decisórias das políticas públicas.

Tais modelos apresentam, inclusive, um importante potencial analítico para a investigação da implementação propriamente dita da BNCC nos estados e municípios. Conforme explorado na seção anterior, o processo de produção da política, sobretudo após 2016, tem sido marcado pelo protagonismo desses atores não estatais (institutos, fundações, editoras e demais empresas ligadas ao setor educacional), que vêm ampliando ainda mais seu poder de influência nas ações de indução à implementação da reforma curricular, devido à baixa coordenação desse processo entre os entes federados, por parte da União. Desse modo, torna-se praticamente impossível abarcar a complexidade desse processo - e os conflitos que dele resultam - apenas com referência às duas abordagens antagônicas que inauguraram os estudos de implementação. Nesse sentido, também buscamos apresentar, na seção anterior, algumas possibilidades de estudos futuros que podem ser delineados a partir da melhor compreensão do contexto que se apresenta para essa implementação (político, ou até mesmo simbólico) - objetivo principal do presente trabalho.

Reconhecendo o caráter preliminar dessas considerações e a impossibilidade de nos debruçarmos com maior profundidade sobre um processo ainda incipiente, buscamos lançar luz sobre possíveis contribuições da literatura de implementação de políticas públicas para a análise de políticas educacionais, que comumente apresentam um grau significativo de conflito. 


\section{REFERÊNCIAS}

AVELAR; Marina; BALL, Stephen J. Mapping the new philanthropy and the heterarchical state: The Mobilization for the National Learning Standard in Brazil. International Journal of Educational Development, [s. l.], v. 64, p. 65-73, 2019. Disponível em: https:// doi.org/10.1016/j.ijedudev.2017.09.007. Acesso em: 28 jan. 2021.

BARRETT, Susan M. Implementation studies: time for a revival? Personal reflections on 20 years of implementation studies. Public Administration, Oxford, v. 82, n. 2, p. 249-262, 2004. Disponível em: https://perguntasaopo.files.wordpress.com/2014/06/sbarrett-implementacao.pdf. Acesso em: 28 jan. 2021.

BICHIR, Renata. Para além da "fracassomania": os estudos brasileiros sobre implementação de políticas públicas. In: MELLO, Janine et al. (org.). Implementação de políticas e atuação de gestores públicos - experiências recentes das políticas das desigualdades. Brasília: Ipea, 2020. p. 23-43.

BONAMINO, Alicia; MARTÍNEZ, Sílvia Alícia. Diretrizes e Parâmetros Curriculares Nacionais para o ensino fundamental: A participação das instâncias políticas do estado. Educação e Sociedade, Campinas, v. 23, n. 80, p. 368-385, set. 2002. Disponível em: $\mathrm{http}$ //cev.org.br/biblioteca/diretrizes-parametros-curriculares-nacionais-para-o-ensinofundamental-participacao-das-instancias-politicas-estado/. Acesso em: 28 jan. 2021.

BRASIL. [Constituição (1988)]. Constituição da República Federativa do Brasil. Brasília, DF: Senado Federal, [2020]. Disponível em: http://www.planalto.gov.br/ ccivil_03/constituicao/constituicao.htm. Acesso em: 28 jan. 2021.

BRASIL. Lei 9.394, de 20 de dezembro de 1996. Estabelece as Diretrizes e Bases da Educação Nacional. Diário Oficial da União: seção 1, Brasília, DF, v. 134, n. 248, p. 27833-841, 23 dez. 1996.

BRASIL. Ministério da Educação e do Desporto. Secretaria de Educação Fundamental. Parâmetros curriculares nacionais: introdução aos parâmetros curriculares nacionais. Brasília, DF: MEC: SEF, 1997.

BRASIL. Presidência da República. Lei $n^{\circ} 13.005$, de 25 de junho de 2014. Aprova o Plano Nacional de Educação - PNE e dá outras providências. Brasília, DF: Presidência da República, 2014. Disponível em: https://www2.camara.leg.br/legin/fed/lei/2014/ lei-13005-25-junho-2014-778970-publicacaooriginal-144468-pl.html. Acesso em: 28 jan. 2021.

BRASIL. Guia de implementação da Base Nacional Comum Curricular. Brasília, DF: MEC, 2020. Disponível em: https://implementacaobncc.com.br/wp-content/ uploads/2020/02/guia_implementacao_bncc_atualizado_2020.pdf. Acesso em: 23 dez. 2020 . 
COSTA, Vanessa do Socorro Silva da Costa. Base Nacional Comum Curricular como Politica de Regulação do Currículo, da Dimensão Global ao Local: o que pensam os professores? 2018. 185 f. Tese (Doutorado em Educação) - Pontifícia Universidade Católica de São Paulo, São Paulo, 2018.

CENPEC. Consensos e Dissensos sobre a Base Nacional Comum Curricular. São Paulo: Cenpec, 2015. Disponível em: http://www.cenpec.org.br/2015/09/21/relatorioda-pesquisa-consensos-e-dissensos-sobre-a-base-nacional-comum-curricular. Acesso em: 29 jun. 2019.

COSSETIN, Vânia Lisa Fischer. Uma leitura ambivalente sobre a adoção de uma base curricular nacional: para fazer justiça à reflexividade da filosofia da educação. Educar em Revista, Curitiba, v. 33, n. 66, p. 295-311, 2017. Disponível em: https://www.scielo. br/j/er/a/wRgp9Hcwfwy3ztbPNdKvSyL/?lang=pt. Acesso em: 28 jan. 2021.

EDITORA MODERNA. BNCC: Material de Referência Pedagógica. [S. l.]: Editora Moderna, 2018. Disponível em: https:/pt.calameo.com/read/002899327fffb325821ff? authid=QwwmixyOlUkJ. Acesso em: 10 dez. 2019.

FARIA, Carlos Aurélio Pimenta de. Implementação: ainda o "elo perdido" da análise de políticas públicas no Brasil. In: FARIA, Carlos A. P. (org.). Implementação de políticas públicas: teoria e prática. Belo Horizonte: Editora PUC Minas, 2012. p. 123-153.

FREITAS, Luiz Carlos. Os reformadores empresariais da educação e a disputa pelo controle do processo pedagógico na escola. Educação e Sociedade, Campinas, v. 35, n. 129, p. 1085-1114, 2014. Disponível em: https://doi.org/10.1590/ES010173302014143817. Acesso em: 28 jan. 2021.

HILL, Michael; HUPE, Peter. The multi-layer problem in implementation research. Public Management Review, London, v. 5, n. 4, p. 471-490, 2003. Disponível em: https://doi. org/10.1080/1471903032000178545. Acesso em: 28 jan. 2021.

HILL, Michael; HUPE, Peter. Implementing public policy: an introduction to the study of operational governance. 3. ed. London: Sage, 2014

HOWLETT, Michael; RAMESH, M.; PERL, Anthony. Política Pública. Seus ciclos e subsistemas. Uma abordagem integral. Tradução técnica: Fernando G. Heidemann. 3. ed. Rio de Janeiro: Elsevier, 2013.

LIPSKY, Michael. Street-level bureaucracy: dilemmas of the individual in public service. New York: Russel Sage Foundation, 1980.

LOTTA, Gabriela Spanghero. Agentes de implementação: uma forma de análise de políticas públicas. Cadernos Gestão Pública e Cidadania, São Paulo, v. 19, n. 65, p. 186-206, jul./dez. 2014. Disponível em: https://doi.org/10.12660/cgpc.v19n65.10870. Acesso em: 28 jan. 2021. 
LOTTA, Gabriela Spanghero. A política pública como ela é: contribuições dos estudos sobre implementação para a análise de políticas públicas. In: LOTTA, Gabriela Spanghero (org.). Teoria e análises sobre implementação de políticas públicas no Brasil. Brasília: Enap, 2019. p. 11-38.

LOTTA et al. Efeito de mudanças no contexto de implementação de uma política multinível: análise do caso da Reforma do Ensino Médio no Brasil. Revista de Administração Pública, Rio de Janeiro, v. 55, n. 2, p. 395-413, mar./abr. 2021. Disponível em: https://doi.org/10.1590/0034-761220190159. Acesso em: 28 jan. 2021.

MAINARDES, Jefferson; STREMEL, Silvana. A teoria de Basil Bernstein e algumas de suas contribuições para as pesquisas sobre políticas educacionais e curriculares. Teias, Rio de Janeiro, v. 11, n. 22, p. 31-54, maio/ago. 2010. Disponível em: https://www.epublicacoes.uerj.br/index.php/revistateias/article/view/24114. Acesso em: 28 jan. 2021.

MATLAND, Richard E. Synthesizing the Implementation Literature: The AmbiguityConflict Model of Policy Implementation. Journal of Public Administration Research and Theory, Oxford, v. 5, n. 2, p. 145-174, Apr. 1995. Disponível em: https://doi.org/10.1093/ oxfordjournals.jpart.a037242. Acesso em: 28 jan. 2021.

MAYNARD-MOODY, Steven; MUSHENO, Michael. Cops, Teachers and Counselors. Ann Arbor: The University of Michigan Press, 2003.

MAZMANIAN, Daniel A.; SABATIER, Paul A. Implementation and Public Policy. Glenview: Scott Foresman, 1983.

PRESSMAN, Jeffrey; WILDAVSKY, Aaron. Implementation: how great expectations in Washington are dashed in Oakland; or Why it's amazing that federal programs work at all, this being the saga of the Economic Development Administration as told by two sympathetic observers who seek to build morals on a foundation of ruined hopes. Berkeley: University of California Press, 1973.

SABATIER, Paul A.; MAZMANIAN, Daniel A. The Conditions of Effective Implementation. Policy Analysis, [s. l.], v. 5, p. 481-504, 1979. Disponível em: https://www. jstor.org/stable/42783358. Acesso em: 28 jan. 2021.

SABATIER, Paul. Top-down and bottom-up approaches to implementation research. In: HILL, Michael (ed.). The policy process: a reader. New York: Harvester/Wheatsheaf, 1993. p. 266-296.

SALDANHA, Paulo. Bolsonaro segura R $\$ 105$ mi e empaca a implementação da base curricular. Folha de São Paulo, São Paulo, 16 set. 2019. Educação. Disponível em: https://www1.folha.uol.com.br/educacao/2019/09/bolsonaro-segura-r-105-mi-e-empacaa-implementacao-da-base-curricular.shtml. Acesso em: 23 dez. 2020.

SÜSSEKIND, Maria Luiza. As (im)possibilidades de uma Base Comum Nacional. Revista e-Curriculum, São Paulo, v. 12, n. 3, p. 1512-1529, 2014. Disponível em: https:// revistas.pucsp.br/index.php/curriculum/article/view/21667. Acesso em: 28 jan. 2021. 
TILIO, Rogério. A Base Nacional Comum Curricular e o contexto brasileiro. In: GERHARDT, Ana Flávia Lopes Magela; AMORIM, Marcel Álvaro de (org.). A BNCC e o ensino de línguas e literaturas. Campinas: Pontes Editores, 2019. p. 7-15.

WINTER, Soeren. Implementation Barriers (in Danish). Politica, [s. l.], v. 17, n. 4, p. 467-487, 1985. Disponível em: http://himia.umj.ac.id/wp-content/uploads/2020/04/B.Guy-Peters-ed.-Jon-Pierre-ed.-Handbook-of-Public-Policy-Sage-Publications-2006.pdf. Acesso em: 20 jan. 2021.

WINTER, Soeren. Implementation. In: PETERS, B. Guy; PIERRE, Jon (ed.). Handbook of public policy. London: Sage Publishing, 2006. p. 151-166. Disponível em: http://himia. umj.ac.id/wp-content/uploads/2020/04/B.-Guy-Peters-ed.-Jon-Pierre-ed.-Handbook-ofPublic-Policy-Sage-Publications-2006.pdf. Acesso em: 28 jan. 2021.

Texto recebido em $20 / 01 / 2021$.

Texto aprovado em 07/08/2021. 